\title{
Risk factors associated with musculoskeletal disorders of the neck and shoulder in the personnel of Kerman University of Medical Sciences
}

\author{
Farzan Madadizadeh ${ }^{1,2}$, Leila Vali $^{3}$, Sima Rafiei $^{4}$, Zahra Akbarnejad $^{5}$
}

\footnotetext{
${ }^{1}$ Noncommunicable Diseases Research Center, Fasa University of Medical Sciences, Fasa, Iran

${ }^{2}$ Ph.D. Student of Biostatistics, Department of Epidemiology and Biostatistics, School of Public Health, Tehran University of Medical Sciences, Tehran, Iran

${ }^{3}$ Assistant Professor, Environmental Health Engineering Research Center, Kerman University of Medical Sciences, Kerman, Iran

${ }^{4}$ Assistant Professor, Department of Health Management, School of Health, Qazvin University of Medical Sciences, Qazvin, Iran

${ }^{5}$ B.Sc. Students, Modeling in Health Research Center, Institute for Futures Studies in Health, Kerman University of Medical Sciences, Kerman, Iran
}

Type of article: Original

\begin{abstract}
Background: Musculoskeletal disorders (MSDs) of the neck and shoulder are the most common and most influential factors causing disorder in the performance and absenteeism of work in administrative personnel.

Aim: To identify risk factors which affect musculoskeletal disorders of neck and shoulder areas in headquarters staff of Kerman University of Medical Sciences.

Methods: The present cross-sectional study was conducted in 2015 on 282 headquarters personnel of Kerman University of Medical Sciences (Kerman, Iran). The desired headquarters staff were selected from seven Deputy Vice-Chancellors of Kerman University of Medical Sciences, including Deputy of Health; Deputy of Treatment; Deputy of Education; Deputy of Students and Cultural Affairs; Deputy of Food and Drugs; Deputy of Management Development and Resource Planning; Deputy of Research and Technology, and data were gathered by using a standard Nordic musculoskeletal questionnaire NMQ (Nordic) and were analyzed by using SPSS version 16. The impact of various factors on the most common complications (neck and shoulder pains) was analyzed separately through logistic regression analysis and detailed Odds Ratio (OR) was calculated for each individual.

Results: The occurrence of neck and shoulder pains in headquarters staff were $42.14 \%$ and $40.71 \%$, respectively. In the prevalence of neck pain variables such as marital status (single than married $\mathrm{p}=0.01, \mathrm{OR}=0.24$ ), work experience ( $\mathrm{p}=0.03, \mathrm{OR}=1.07$ ), education (bachelor's degree and lower than master's degree and higher $\mathrm{p}=0.003$, $\mathrm{OR}=2.69)$, right $/$ left-handedness (left than right $\mathrm{p}=0.03$, $\mathrm{OR}=0.33)$, weight $(\mathrm{p}=0.04, \mathrm{OR}=1.04)$, place of work $(\mathrm{p}<0.05)$; as well as in the prevalence of shoulder pain variables such as marital status (single than married $\mathrm{p}=0.04, \mathrm{OR}=0.48)$, work experience $(\mathrm{p}=0.01, \mathrm{OR}=1.20)$, education (bachelor and lower than master and higher $\mathrm{p}=0.04, \mathrm{OR}=1.97)$, right $/$ left handedness (left than right $\mathrm{p}=0.01, \mathrm{OR}=0.42)$, age $(\mathrm{p}=0.02, \mathrm{OR}=1.05)$, and gender (male than female $\mathrm{p}=0.03$, OR=0.65) affected.

Conclusion: The results of this study showed that the prevalence of neck and shoulder pains is influenced by various risk factors and some of which were identified and an amount of their influence in this study was found. Therefore, it is suggested by considering the risk factors and planning control programs, a major step is taken in reducing the musculoskeletal disorders of office staff.
\end{abstract}

Keywords: Musculoskeletal disorders, Neck pain, Shoulder pain, Office staff, Risk factor

\section{Corresponding author:}

Assistant Professor Dr. Leila Vali, Environmental Health Engineering Research Center, Kerman University of Medical Sciences, Kerman, Iran. Tel: +98.9123062803, Email: vali1386@gmail.com

Received: February 24, 2016, Accepted: August 03, 2016, Published: May 2017

iThenticate screening: July 24, 2016, English editing: February 18, 2017, Quality control: March 27, 2017

(C) 2017 The Authors. This is an open access article under the terms of the Creative Commons Attribution-NonCommercialNoDerivs License, which permits use and distribution in any medium, provided the original work is properly cited, the use is non-commercial and no modifications or adaptations are made. 


\section{Introduction}

Musculoskeletal disorders are a series of inconveniences, harm, and pain caused by different factors in different parts of the body, and in the long term, prevent the sufferer from carrying out general day-to-day activities (1). Musculoskeletal disorders are a multi-factorial phenomenon created as a result of various risk factors. One of the risk factors is inappropriate posture of the body. Even if the situation is appropriate, prolonged static position can still increase damage (2). Today, with the increasing development of science and technology, incidence of stagnation and inactivity, fatigue, and musculoskeletal disorders have increased in patients (3). The work environment, due to non-compliance with some ergonomic principles, are the grounds for major musculoskeletal disorders, and proper planning and management can significantly reduce the rate of these disorders. Half of workrelated diseases are caused by musculoskeletal disorders and they are the main cause of time wasting and cost overruns. Feeling of pain and disability in various parts of the musculoskeletal system is among the main difficulties of working in office environments (4). Complications of neck and shoulder pains are the main reasons for absence in an office environment, and have accounted for more than half of workplace absences (1). In most of the administrative work that requires extensive use of the eyes, there are neck and shoulder disorders that are mainly due to prolonged use of computers by personnel $(1,4)$. In studies conducted in different countries, a high prevalence of musculoskeletal disorders among office staff has been reported and the most affected areas have been neck and shoulders (4-9). Musculoskeletal disorders affect the performance of office staff in various forms, they affect, for example, the quality of the employee's performance and skill, and sometimes undermines the respect and professional relationship between employees and clients (5). In America and Canada respectively 1.3\% and 2.4\% of revenue is spent annually on treatment costs of musculoskeletal disorders and diagnosis and treatment in the US alone comes to tens of billions of dollars (10), although, in Iran also, a huge amount is spent annually to treat patients with musculoskeletal disorders, precise knowledge of these costs is not available. Since the prevalence of these disorders creates many human and financial losses, preventing them seems necessary. According to some studies (7-9), which trace the roots of musculoskeletal disorders of neck and shoulder areas, as well as influencing factors in office staff, there was a need to study this issue in one of the major universities of medical sciences in Iran. Kerman University of Medical Sciences, in terms of size and population, is considered among the popular universities of medical sciences in Iran. So far, such research has not been done in headquarters staff. Therefore, it was a good choice for this study. This study aimed to identify factors affecting the musculoskeletal disorders of neck and shoulder areas in headquarters staff of Kerman University of Medical Sciences.

\section{Material and Methods}

In this cross-sectional study in 2015, 282 members of staff from headquarters of Kerman University of Medical Sciences were selected, and entered the study through stratified sampling proportional to size from various departments of the university. Sample size was calculated by a pilot study, and measuring the prevalence of $20 \%$, taking into account the Type I error and the accuracy 5\% by Cochran formula, and was equal to 245 people. In addition to addressing the lack of accountability of staff and sample attrition, the final size considered 282 people by calculating 15\% increase. The headquarters staff were working in 7 departments of the university; therefore, each department sampling was considered as a stratum and then by using proportionate stratified random sampling from each department proportional to the size of the total population of headquarters staff of Kerman University of Medical Sciences, random sampling was done. To collect data, a standardized Nordic musculoskeletal questionnaire was used. This questionnaire is among the most common assessment tools of musculoskeletal disorders, designed in 1987 by Kuorinka et al. at the Center of Occupational Health in Scandinavia, and from that time until now with maintaining the position, has been used as a standard tool for collecting information about work-related musculoskeletal disorders and estimating their prevalence rate (11).

Validity of the questionnaire was confirmed by ergonomics specialists and generally the internal reliability of the questionnaire was obtained through Cronbach's alpha with coefficient 0.85 and the external reliability through testretest with intraclass correlation 0.81 . Demographic data of the questionnaire included questions about gender, age, weight, height, number of children, work experience, education, work place, left / right handedness. The symptoms of musculoskeletal disorders considered in this study included neck and shoulder discomfort and pain. Questionnaires were completed by obtaining consent by staff in their work place. The data was described by using descriptive statistics and then by binary logistic regression analysis, the relationship of demographic factors and disorder prevalence of neck and shoulders was investigated separately in univariate and also multivariate mode by adjusting the effects of other variables. Data analysis was done by software SPSS version 16 and considering the significance level of $5 \%$. 


\section{Results}

In this study, the 282 headquarters personnel of Kerman University of Medical Sciences were 41 people (14.5\%) from the deputy of health, 40 people (14.2) from the deputy of students and cultural affairs, 42 people (14.9\%) from the deputy of education, 40 people (14.2\%) from the deputy of food and drug, 40 people (14.2\%) from the deputy of research and technology, and 39 people (13.8\%) from the deputy of management and resources development. A total of 180 people $(63.8 \%)$ of the population were female, 215 people $(76.2 \%)$ were married, the mean (SD) of age was 38.8 (7.9), the mean (SD) of working experience 14.8 (6.6), the mean (SD) of weight 69.5 (13.3), the mean (SD) of height 166.7 (9.06), and 202 people (71.6\%) had bachelor degree and less, $226(94.2 \%)$ were right-handed, and 270 people $(95.7 \%)$ had less than 3 children. The results showed that generally, the prevalence of neck pain in the previous 12 months was $42.14 \%$ (119 people) and the prevalence of shoulder pain was $40.71 \%$ (115 people). In addition, these amounts, in the last week were $27.82 \%$ ( 81 people) and $27.14 \%$ (76 people) respectively. In the last year, 90 people (31.91\%), due to the complication of neck pain and 69 people (24.4\%), due to the complication of shoulder pain were not present in their work places. The relationship of demographic variables with the occurrence of neck and shoulder pain complications was investigated through the analysis of univariate and multivariate binary logistic regression and is presented in Table 1 and 2.

Table 1. Relationship between Demographic Characteristics and Complication of Neck Pain: Logistic Regression Analysis

\begin{tabular}{|c|c|c|c|c|c|c|c|}
\hline Variables & Levels & $\begin{array}{l}\text { Crude } \\
\text { OR }\end{array}$ & CI $95 \%$ & $p$ & $\begin{array}{l}\text { Adjusted } \\
\text { OR }\end{array}$ & CI $95 \%$ & $p$ \\
\hline Age & - & 1.02 & $0.99-1.05$ & 0.11 & 0.96 & $0.89-1.04$ & 0.349 \\
\hline \multirow[t]{2}{*}{ Sex } & Male & 0.72 & $0.43-1.18$ & 0.195 & 0.52 & $0.24-1.17$ & 0.115 \\
\hline & Female & 1 & - & - & 1 & - & - \\
\hline \multirow[t]{2}{*}{ Marital Status } & Single & 0.4 & $0.21-0.74$ & 0.004 & 0.24 & $0.19-0.42$ & 0.01 \\
\hline & Married & 1 & - & - & 1 & - & - \\
\hline Work Experience & - & 1.04 & $1.01-1.10$ & 0.009 & 1.07 & $1-1.11$ & 0.03 \\
\hline \multirow[t]{2}{*}{ Educational Level } & $\begin{array}{l}\text { BS Degree or } \\
\text { Lower }\end{array}$ & 2.7 & $1.95-3.69$ & 0.0001 & 2.69 & $1.99-3.18$ & 0.003 \\
\hline & MSc or Upper & 1 & - & - & 1 & - & - \\
\hline \multirow{3}{*}{$\begin{array}{l}\text { Number of } \\
\text { Children }\end{array}$} & 0 & 1.13 & $0.34-3.67$ & 0.84 & 1.92 & $0.48-4.63$ & 0.35 \\
\hline & $1-3$ & 0.82 & $0.24-1.8$ & 0.75 & 5.28 & $3.94-9.56$ & 0.06 \\
\hline & $3-5$ & 1 & - & - & 1 & - & - \\
\hline Weight & - & 1.03 & $\begin{array}{l}1.004- \\
1.09\end{array}$ & 0.02 & 1.04 & $1.002-1.11$ & 0.04 \\
\hline Height & - & 1.006 & $0.97-1.04$ & 0.7 & 1.01 & $0.96-1.06$ & 0.58 \\
\hline \multirow{2}{*}{ Right Hand } & No & 0.169 & $0.14-0.25$ & 0.02 & 0.33 & $0.26-0.51$ & 0.03 \\
\hline & Yes & 1 & - & - & 1 & - & - \\
\hline \multirow[t]{7}{*}{ Work Place } & A & 0.58 & $0.24-1.39$ & 0.22 & 0.37 & $0.13-0.57$ & 0.024 \\
\hline & $\mathrm{B}$ & 0.44 & $0.28-0.79$ & 0.08 & 0.23 & $0.18-0.42$ & 0.007 \\
\hline & $\mathrm{C}$ & 0.32 & $0.18-0.56$ & 0.015 & 0.17 & $0.11-0.29$ & 0.001 \\
\hline & $\mathrm{D}$ & 0.54 & $0.23-1.32$ & 0.18 & 0.33 & $0.12-0.41$ & 0.03 \\
\hline & $\mathrm{E}$ & 0.32 & $0.14-0.48$ & 0.01 & 0.18 & $0.16-0.34$ & 0.002 \\
\hline & $\mathrm{F}$ & 0.42 & $0.17-0.66$ & 0.06 & 0.17 & $0.11-0.39$ & 0.001 \\
\hline & $\mathrm{G}$ & 1 & - & - & 1 & - & - \\
\hline
\end{tabular}

A: Deputy of Health; B: Deputy of Treatment; C: Deputy of Education; D: Deputy of Students and Cultural Affairs; E: Deputy of Food and Drugs; F: Deputy of Management Development and Resource Planning; G: Deputy of Research and Technology.

As it can be seen from Table 1, the relationship between age and occurrence of neck pain is not statistically significant ( $\mathrm{p}=0.34)$. The relationship between marital status and occurrence of neck pain is significant; therefore, the occurrence risk of neck pain in single people is $76 \%$ less than married people $(\mathrm{p}=0.01, \mathrm{OR}=0.24)$. The relationship between work experience and occurrence of neck pain is significant; therefore, the occurrence risk of neck pain increases $7 \%$ for every one-year increase in work experience $(\mathrm{p}=0.03, \mathrm{OR}=1.07)$. The relationship between education and occurrence of neck pain is significant; therefore, the occurrence risk of neck pain in people with a bachelor's degree and less is $2.7 \%$ times more than people with master's and doctoral degrees ( $\mathrm{p}=0.003$, 
$\mathrm{OR}=2.69$ ). The relationship between weight and occurrence of neck pain is significant; therefore, the occurrence risk of neck pain increases $4 \%$ for every kilogram increase in weight $(\mathrm{p}=0.04, \mathrm{OR}=1.04)$. The relationship between right or left-handedness and occurrence of neck pain is significant; therefore, the occurrence risk of neck pain in lefthanded people is $67 \%$ less than right-handed people $(\mathrm{p}=0.02, \mathrm{OR}=0.33)$. In addition, the relationship between place of work and occurrence of neck pain is statistically significant; therefore, the occurrence risk of neck pain in each deputy compared with the deputy of research was respectively as follows: the deputy of health is $63 \%$ less ( $\mathrm{p}=0.024$, $\mathrm{OR}=0.37)$, deputy of treatment $77 \%$ less $(\mathrm{p}=0.007, \mathrm{OR}=0.23)$, deputy of education $83 \%$ less $(\mathrm{p}=0.001, \mathrm{OR}=0.17)$, deputy of students $67 \%$ less $(\mathrm{p}=0.03$, $\mathrm{OR}=0.33)$, deputy of food and drug $81 \%$ less $(\mathrm{p}=0.002, \mathrm{OR}=0.19)$, and deputy of management development and resource planning $83 \%$ less $(\mathrm{p}=0.001, \mathrm{OR}=0.17)$. The information in Table 2 show that the relationship between age and occurrence of shoulder pain is statistically significant in univariate; therefore, the occurrence risk of shoulder pain increases by $5 \%$ per year in age $(\mathrm{p}=0.001, \mathrm{OR}=1.05)$. The relationship between gender and the occurrence of shoulder pain is statistically significant in univariate; therefore, the occurrence risk of shoulder pain in men is $40 \%$ less than in women $(\mathrm{p}=0.04, \mathrm{OR}=0.6)$; however, in multivariate mode, by adjusting the effects of other variables, this relationship was not significant ( $p>0.05)$. In addition, the relationship between marital status and the occurrence of shoulder pain was statistically significant; therefore, the occurrence risk of shoulder pain in single people was $52 \%$ less than married people $(\mathrm{p}=0.04, \mathrm{OR}=0.48)$. The relationship between work experience and the occurrence of shoulder pain was statistically significant; therefore, the occurrence risk of shoulder pain increases by $2 \%$ per year in work experience $(\mathrm{p}=0.01, \mathrm{OR}=1.02)$. The relationship between education and the occurrence of shoulder pain was statistically significant; therefore, the occurrence risk of shoulder pain in people with bachelor's degree and lower education was about two times more than people with master's and doctoral education $(\mathrm{p}=0.04, \mathrm{OR}=1.97)$. The relationship between the occurrence of shoulder pain and right $/$ lefthandedness was statistically significant; therefore, the occurrence risk of shoulder pain in left-handed people was $58 \%$ less than right-handed ones $(\mathrm{p}=0.02$, $\mathrm{OR}=0.42)$.

Table 2. Relationship between Demographic Characteristics and Complication of Shoulder Pain: Logistic Regression Analysis

\begin{tabular}{|c|c|c|c|c|c|c|c|}
\hline Variables & Levels & Crude OR & CI $95 \%$ & $p$ & Adjusted OR & CI $95 \%$ & $p$ \\
\hline Age & - & 1.07 & $1.04-1.11$ & 0.001 & 1.05 & $1.00-1.13$ & 0.02 \\
\hline \multirow[t]{2}{*}{ Sex } & Male & 0.6 & $0.46-0.91$ & 0.04 & 0.65 & $0.39-0.87$ & 0.03 \\
\hline & Female & 1 & - & - & 1 & - & - \\
\hline \multirow[t]{2}{*}{ Marital Status } & Single & 0.47 & $0.25-0.53$ & 0.01 & 0.48 & $0.37-0.66$ & 0.04 \\
\hline & Married & 1 & - & - & 1 & - & - \\
\hline Work Experience & - & 1.06 & $1.03-1.19$ & 0.0001 & 1.20 & $1.00-1.34$ & 0.01 \\
\hline \multirow[t]{2}{*}{ Educational Level } & BS Degree or Lower & 2.48 & $2.22-3.38$ & 0.0001 & 1.97 & $1.74-2.29$ & 0.04 \\
\hline & MSc or Upper & 1 & - & - & 1 & - & - \\
\hline \multirow[t]{3}{*}{ Number of Children } & 0 & 0.45 & $0.21-1.39$ & 0.71 & 0.42 & $0.31-1.27$ & 0.90 \\
\hline & $1-3$ & 0.62 & $0.29-1.4$ & 0.67 & 0.57 & $0.31-2.8$ & 0.88 \\
\hline & $3-5$ & 1 & - & - & 1 & - & - \\
\hline Weight & - & 0.99 & 0.86-1.03 & 0.03 & 0.98 & 0.91-1.19 & 0.48 \\
\hline Height & - & 0.97 & 0.94-1.04 & 0.02 & 1.007 & $0.77-1.26$ & 0.76 \\
\hline \multirow[t]{2}{*}{ Right Hand } & No & 0.18 & $0.11-0.29$ & 0.02 & 0.42 & $0.19-0.52$ & 0.01 \\
\hline & Yes & 1 & - & - & 1 & - & - \\
\hline \multirow[t]{7}{*}{ Work Place } & A & 0.64 & $0.26-1.5$ & 0.32 & 0.54 & $0.20-1.40$ & 0.22 \\
\hline & $\mathrm{B}$ & 0.74 & $0.3-1.7$ & 0.50 & 0.65 & $0.24-1.8$ & 0.39 \\
\hline & $\mathrm{C}$ & 0.53 & $0.21-1.31$ & 0.17 & 0.37 & $0.13-1.03$ & 0.06 \\
\hline & $\mathrm{D}$ & 0.81 & $0.43-1.90$ & 0.65 & 0.67 & $0.25-1.30$ & 0.43 \\
\hline & $\mathrm{E}$ & 0.83 & $0.34-1.13$ & 0.69 & 0.60 & $0.43-0.79$ & 0.03 \\
\hline & $\mathrm{F}$ & 0.85 & $0.73-2.07$ & 0.70 & 0.56 & $0.42-1.5$ & 0.26 \\
\hline & $\mathrm{G}$ & 1 & - & - & 1 & - & - \\
\hline
\end{tabular}

A: Deputy of Health; B: Deputy of Treatment; C: Deputy of Education; D: Deputy of Students and Cultural Affairs; E: Deputy of Food and Drug; F: Deputy of Management Development and Resource Planning; G: Deputy of Research and Technology. 


\section{Discussion}

In this study, conducted to identify the influencing risk factors and the amount of impact on neck and shoulder disorders in headquarters personnel of Kerman University of Medical Sciences, from a total 282 people participating in the study in 12 months, 119 patients (42.14\%) suffered from neck pain, 115 patients $(40.71 \%)$ from shoulder pain, and generally 117 patients $(41.48 \%)$ of 282 patients had disorders in at least one area of neck and shoulder in the last year. The results showed that the highest prevalence rate of disorders in the neck was $42 \%$ and this was consistent with previous studies with the prevalence rate of 27 to $63 \%$. For example, in the study of Wu et al. in 2012 , conducted to identify musculoskeletal disorders among office staff in China, the highest prevalence of neck and shoulder pain was estimated at $55 \%$ and $57 \%$ respectively $(9,12,13)$. With regards to sitting still on a chair, working with a computer, and unergonomic furniture this problem is not unexpected. Mansouri et al., in a study investigating the factors affecting neck pain among office workers, found that gender is an influencing factor on the occurrence of neck pain (14). However, in the present study by multiple logistic regression analysis and adjusting the effects of other variables, the effect of this factor was not statistically significant and was not known to be influential. It can be said, the issue that the gender variable was significant in their study was due to the effects of other variables. The occurrence risk of neck pain complication in single people is $76 \%$ less than married people $(\mathrm{p}=0.01, \mathrm{OR}=0.24)$ or on the contrary, married people suffer 4 times more than single people from this complication $(1 / \mathrm{OR}=1 / 0.24=4.16)$. This can be due to differences in lifestyle or marital problems. Unlike the findings of this study, this factor was not known to be significant in other studies and even the effect of this factor was not investigated in some studies $(4,15,16)$. Analysis of this study showed that work experience has a significant relationship with the occurrence of neck pain; therefore, for every one-year increase in work experience, the occurrence risk of neck pain in personnel will be increased 7\%. Choobineh et al., in their study, focused on the significance of this factor and stated that by increasing work experience, the prevalence of musculoskeletal disorders will be increased (17). Results of previous studies show that some are consistent and some are in contrast to this issue, and have introduced work experience as ineffective factors in musculoskeletal disorders $(9,13,14,17)$. It can be said that in the previous studies the effect of other confounding variables was not controlled, but in this study using multiple logistic regression, the effect of all other variables was adjusted and the result is closer to the truth. The findings showed that the variable of education level has a significant relationship with the occurrence of neck pain. Therefore, people with bachelor's education and lower than those with master's and doctoral education are about 3 times more at risk of suffering neck pain $(\mathrm{p}=0.003, \mathrm{OR}=2.69)$. This variable was considered effective in some of the previous studies and ineffective in some others on the occurrence of musculoskeletal disorders (4, 14, 18); however, in none of the previous studies, was it explained so tangibly as in the present study. To justify that this variable is significant, it can be said that the possible reason is difference between organizational positions and decreasing physical labor or work difficulties in master's and doctoral graduates. Studying the data of this research showed that although by increasing child number, the risk of neck pain will be increased 5 times more, this amount is not statistically significant. This finding is consistent with previous studies $(12,13)$. Our findings showed that weight variable is an effective factor in the occurrence of neck pain. Therefore, with 10 kilos increase of weight, the occurrence risk of neck pain will be increased $62 \%$. The results of previous studies showed the significant impact of this factor on the occurrence of musculoskeletal disorders, but none mentioned gave an explanation as clearly as that which was stated in this study $(5,6,19)$. Although in this study it was shown that for each centimeter increase in height the risk of neck pain occurrence would be increased 1\%, unlike some previous studies, this amount was not statistically significant $(2,5,17)$.

The results of this study showed a significant relationship between the occurrence of neck pain with right / lefthandedness; therefore, left-handed people are 67\% less likely to develop neck pain disorder. This result was not consistent with the study results of Choobineh et al. who did not recognized this factor as effective (17). Since, in the study of Choobineh, the other variables were not adjusted, the fact that this variable was not significant may be due to confounding effects of other variables in their study. However, in this study, the effects of other variables were completely adjusted by multiple logistic regression and their significance was not influenced by any factors. The findings of this study showed that there is a significant relationship between service place of personnel and neck pain occurrence; therefore, personnel of other deputies had less risk of neck pain occurrence than the personnel of research deputy. It should be noted that the occurrence rate of neck pain is very high and about 55\% in research deputy. The reason of higher prevalence of neck pain in research deputy may be that the personnel of this deputy spend most of their time working with computers. The effect of this variable was studied in a number of previous studies (13). This study investigated also the possible risk factors for the occurrence of shoulder pain and the results are as follows: The age variable in the absence of other variables in the study is an affecting factor and statistically significant in the occurrence of shoulder pain among staff; therefore, for every 10-year increase in age, the 
occurrence risk of shoulder disorders is increased to about $62 \%$. In line with our findings, Nourouzi et al. found in their study that by increasing age, the occurrence rate of musculoskeletal disorders will be increased (9). The results of the present study showed that the relationship between gender and the occurrence of shoulder pain disorders is statistically significant; therefore, the occurrence risk of shoulder pain in men is $35 \%$ less than women. In explaining the cause, it can be said that the muscular system of men is stronger than women. This result is consistent with results of previous studies that revealed women are more at risk of shoulder pain $(5,7)$. Our results showed a significant relationship between marital status and shoulder pain; therefore, the occurrence risk of shoulder pain in married people was about 2 times more than single people and it may be because of the difficulties of married life and increasing individual responsibility. In comparing the present study with previous ones, it can be said there are contradictory statements in the previous research; therefore, the present study is consistent with some of them $(1,15$, 16). The results showed that the variable of work experience has a significant relationship with the occurrence of shoulder pain; therefore, for every 10 -years of work experience increase the occurrence risk of shoulder pain will be increased about $20 \%$. This finding is consistent with previous findings and a majority of previous studies acknowledged the significant impact of this factor on musculoskeletal disorders $(9,14,18)$.

The results of this study showed that there is a significant relationship between the level of education and the occurrence of shoulder pain; therefore, the occurrence risk of neck pain in the personnel of diploma and lower is about 2 times more than the personnel of master's and doctoral education. To justify that, it may be said post graduated personnel have better organizational positions and more time to rest. This finding is consistent with findings from previous studies that the education variable is a significant risk factor for the occurrence of musculoskeletal disorders $(7,13,19)$. In this study, after the required analysis, the variable of child number was known as an ineffective factor on the occurrence of shoulder pain, and its relationship with the occurrence of shoulder pain was not statistically significant. Although this finding has been investigated in a few researches, the results are consistent $(16,19)$. The relationship between two variables of height and weight with the occurrence of shoulder pain in this study were not considered statistically significant. This finding was in contrast to previous research; therefore, in most previous researches, these two variables have been identified as factors affecting musculoskeletal disorders $(6,7)$. To justify this, it can be said that in any of the previous studies the effects of other confounding variables were uncontrolled. Also in this study, these two factors were significant in univariate, but by adjusting the effects of other variables (multivariate logistic regression mode) it was shown that this relationship was not significant. On the other hand, it can be said that in similar studies, factors affecting pain have not been investigated separately in each area of the body, so these two variables may be associated with the occurrence of other disorders in other parts of the body and generally have affected disorders of the body. The results also showed that there is a statistically significant relationship between right / left handedness and the occurrence of shoulder pain; therefore, the occurrence risk of shoulder disorders in left-handed is 58\% less than right-handed people or in other words the occurrence risk of shoulder pain in right-handed people is approximately 1.72 times greater than left-handed. This issue has been studied in a number of previous studies, such as Othman's study who only described that, and did not address the relationship between this factor and the occurrence of any complication in body (5). The findings of our study indicated that although the occurrence of shoulder pain had no significant relationship with the work place of office staff, the occurrence risk of shoulder pain in the personnel working in the educational deputy was $63 \%$ less than staff working in the research deputy. In other words, the occurrence risk of shoulder pain in personnel of the research deputy was 2.7 times more than in personnel of the education deputy. In previous research the variable of work place was not known as an affecting variable in shoulder pain and this is not consistent with the results of the present study $(9,16,17)$. The reason of inconsistency is investigating the relationship of variables in shoulder pain specifically in the present study and unlike that in previous studies, the relationship investigated pain in all parts of body, generally. Therefore, it seems that the results of specialized investigating of one organ is more accurate than the investigation of all organs.

The strong point of the study was investigating pain professionally and separately in neck and shoulder areas and identifying the influencing factors on them. In all previous studies, influencing factors on body musculoskeletal disorders were investigated as a whole and not for each organ, and so this study is a pioneer in this field. The weakness of this study was lack of identifying the personnel's field of work; therefore, if it had been clear, we could say how the relationship between the occurrence of any complication and organizational position is, or for example, we could investigate which complication occurs more in personnel whose work is related with use of the computer. 


\section{Conclusions}

In summary, the results showed that the high prevalence rate of musculoskeletal disorders of neck and shoulder areas in office staff is affected by risk factors such as age, gender, education, marital status, work experience, height, weight and work place, and women had more disorders than men and research deputy's personnel also had the disorders more than the personnel of other deputies and also increasing work experience, height, and weight were associated with the prevalence rate of these musculoskeletal disorders. It seems that holding training programs to provide the necessary awareness in order to reduce musculoskeletal disorders in headquarters personnel of Kerman University of Medical Sciences and especially the research deputy's personnel is essential. According to the results, the country's health policy makers are suggested to pay attention to the object of musculoskeletal disorders in headquarters staff of University of Medical Sciences and by considering the variables affecting the musculoskeletal disorders, try to decrease the problems and as a result increase the working efficiency of staff, increase services of health field, and decrease the cost of our health.

\section{Acknowledgments:}

The present study is the result of the approved research projects in Kerman University of Medical Sciences, with code of 94.340. The authors hereby appreciate the sincere cooperation of all office staff of Kerman University of Medical Sciences in collecting data of this research.

\section{Conflict of Interest:}

There is no conflict of interest to be declared.

\section{Authors' contributions:}

All authors contributed to this project and article equally. All authors read and approved the final manuscript.

\section{References:}

1) Collins JD, O'Sullivan LW. Musculoskeletal disorder prevalence and psychosocial risk exposures by age and gender in a cohort of office based employees in two academic institutions. International Journal of Industrial Ergonomics. 2015;46(3):85-97. https://doi.org/10.1016/j.ergon.2014.12.013

2) Bonzini M, Veronesi G, Conti M, Coggon D, Ferrario MM. Is musculoskeletal pain a consequence or a cause of occupational stress? A longitudinal study. International archives of occupational and environmental health. 2015;88(5):12-67. https://doi.org/10.1007/s00420-014-0982-1, PMid: 25261316, PMCid: PMC4437793

3) Mustard CA, Chambers A, Ibrahim S, Etches J, Smith P. Time trends in musculoskeletal disorders attributed to work exposures in Ontario using three independent data sources, 2004-2011. Occupational and environmental medicine. 2015;72(4:(252-257.

4) Karwan M, Azuhairi A, Hayati K. Predictors of upper limb disorders among a public university workers in malaysia. international journal of public health and clinical sciences. 2015;2(3):133-150.

5) Abdullah MZ, Othman AK, Ahmad MF, Justine M. The Mediating Role of Work-Related Musculoskeletal Disorders on the Link between Psychosocial Factors and Absenteeism among Administrative Workers. Social work in public health. 2015;30(1):64-74. https://doi.org/10.1080/19371918.2014.938393, PMid: 25375935

6) Alghadir A, Zafar H, Iqbal ZA. Work-related musculoskeletal disorders among dental professionals in Saudi Arabia. Journal of physical therapy science. 2015;27(4):7-11. https://doi.org/10.1589/jpts.27.1107, PMid: 25995567, PMCid: PMC4433988

7) Brandt M, Sundstrup E, Jakobsen MD, Jay K, Colado JC, Wang Y, et al. Association between neck/shoulder pain and trapezius muscle tenderness in office workers. Pain research and treatment. 2014;35(2)27-35. https://doi.org/10.1155/2014/352735

8) Davis KG, Kotowski SE. Postural Variability An Effective Way to Reduce Musculoskeletal Discomfort in Office Work. Human Factors: The Journal of the Human Factors and Ergonomics Society. 2014;56(7):4961. https://doi.org/10.1177/0018720814528003

9) Noroozi MV, Hajibabaei M, Saki A, Memari Z. Prevalence of Musculoskeletal Disorders Among Office Workers. Jundishapur Journal of Health Sciences. 2015;7(1):10-22(In Persion).

10) Hoy DG, Smith E, Cross M, Sanchez-Riera L, Buchbinder R, Blyth FM, et al. The global burden of musculoskeletal conditions for 2010: an overview of methods. Annals of the rheumatic diseases. 2014; 73(6):982-989. https://doi.org/10.1136/annrheumdis-2013-204344, PMid: 24550172 
11) Dickinson C, Campion K, Foster A, Newman S, O'rourke A, Thomas P. Questionnaire development: an examination of the Nordic Musculoskeletal Questionnaire. Applied ergonomics. 1992;23(3):197-201. https://doi.org/10.1016/0003-6870(92)90225-K

12) Tunwattanapong P, Kongkasuwan R, Kuptniratsaikul V. The effectiveness of a neck and shoulder stretching exercise program among office workers with neck pain: A randomized controlled trial. Clinical rehabilitation. 2015;26(9):47-52.

13) Wu S, He L, Li J, Wang J, Wang S. Visual display terminal use increases the prevalence and risk of workrelated musculoskeletal disorders among Chinese office workers: a cross-sectional study. Journal of occupational health. 2012;54(1):34-43. https://doi.org/10.1539/joh.11-0119-OA, PMid: 22156322

14) Mansouri A, Mohammadi F, Shamsipour M, Makarem J. Neck pain and some of its risk factors among office workers. Knowledge \& health .2012;7(2):27-33

15) Esmaeilzadeh S, Ozcan E, Capan N. Effects of ergonomic intervention on work-related upper extremity musculoskeletal disorders among computer workers: a randomized controlled trial. International archives of occupational and environmental health. 2014;87(1):73-83. https://doi.org/10.1007/s00420-012-0838-5, PMid: 23263694

16) Gorgi Z, Assadollahi Z, Ghaffarian A, Rezaeian M. The Prevalence of Musculoskeletal Disorders in the Employees of Office Systems at Rafsanjan University of Medical Sciences in 2012. Journal of Rafsanjan University of Medical Sciences. 2014;12(12):991-1002 (In Persion).

17) Choobineh A, Rahimi Fard H, Jahangiri M, Mahmood Khani S. Musculoskeletal injuries and their associated risk factors. Iran Occupational Health. 2012;8(4):70-81 (In Persion).

18) Mahmud N, Kenny DT, Zein RM, Hassan SN. The Effects of Office Ergonomic Training on Musculoskeletal Complaints, Sickness Absence, and Psychological Well-Being A Cluster Randomized Control Trial. Asia-Pacific Journal of Public Health. 2015;27(2):1652-1668. https://doi.org/10.1177/1010539511419199, PMid: 21878465

19) Baek JH, Kim YS, Yi KH. Relationship between Comorbid Health Problems and Musculoskeletal Disorders Resulting in Musculoskeletal Complaints and Musculoskeletal Sickness Absence among Employees in Korea. Safety and Health at Work. 2015;6(2):128-133. https://doi.org/10.1016/j.shaw.2015.03.002, PMid: 26106512, PMCid: PMC4476197 